\title{
PEMAHAMAN GURU PRASEKOLAH RAUDHATUL ATHFAL TENTANG KESIAPAN SEKOLAH ANAK
}

\author{
SYARFINA ${ }^{1}$, ELINDRA YETTI $^{2}$, LARA FRIDANI $^{3}$ \\ Universitas Negeri Jakarta \\ ${ }^{1}$ Email: syarfina_s2@mahasiswa.unj.ac.id \\ 2Email: elindrayetti@unj.ac.id \\ Email: lfridani@unj.ac.id
}

\begin{abstract}
Preschool teachers including Raudhatul Athfal (RA) teachers have an important role in building children's school readiness. The purpose of this research is to find out the extent of teachers' understanding on school readiness. The research was conducted by using qualitative approaches. Data were collected through questionnaires distributed to all RA teachers in Langsa, Aceh province. The result shows that the teachers' understanding on school readiness related to children's readiness to enter primary school based on age, independency, and academic ability (write, read and count). The activities implemented by RA teachers in building children's school readiness are by playing, singing, and field trips, using materials such as colors, props, cards, and beams. Teachers assessed children's school readiness by observing daily activities and evaluating student's work. Family factors are considered as a major impact on children's school readiness. Recommendation are made in term of findings is planning some intervention to improve teacher's understanding on children's school readiness concept.
\end{abstract}

Keywords: children's school readiness, preschool teacher, preparedness program,

\begin{abstract}
ABSTRAK: Guru prasekolah termasuk guru Raudhatul Athfal (RA) memiliki peran penting dalam membangun kesiapan sekolah anak. Tujuan dari penelitian ini adalah untuk mengetahui sejauh mana pemahaman guru RA tentang kesiapan sekolah anak. Penelitian dilakukan dengan pendekatan kualitatif. Data dikumpulkan melalui kuesioner yang disebar kepada guru-guru RA di kota Langsa, provinsi Aceh. Hasilnya menunjukkan bahwa guru memahami tentang kesiapan sekolah anak untuk memasuki sekolah dasar berdasarkan usia, kemandirian, dan kemampuan akademik (menulis, membaca dan berhitung). Adapun kegiatan yang dilakukan guru RA dalam membangun kesiapan sekolah anak meliputi bermain, bernyanyi, dan field trip dengan material berupa warna, alat peraga, kartu, dan balok. Guru menilai kesiapan sekolah anak dengan melakukan observasi harian dan evaluasi hasil karya. Faktor keluarga dianggap yang memberi pengaruh besar dalam hal kesiapan sekolah anak. Rekomendasi dari penelitian ini yaitu berupa upaya tindakan untuk meningkatkan pemahaman guru terhadap konsep kesiapan sekolah.
\end{abstract}

Kata kunci: Kesiapan sekolah anak, guru prasekolah, program persiapan. 
Pemahaman Guru Prasekolah......

Syarfina, Elindra, dan Lara Fridani

\section{PENDAHULUAN}

Pendefinisian kesiapan sekolah di dunia internasional sudah diperdebatkan sejak dua dekade silam dalam menentukan sebuah kebijakan (ScottLittle, Kagan, \& Frelow, 2006). Di Indonesia, khususnya di ibukota DKI Jakarta, penelitian tentang kesiapan sekolah dan transisi dilakukan oleh Fridani (2013) terkait perspektif dan praktis dari para guru Taman Kanakkanak (TK) B, guru Sekolah Dasar (SD), orang tua murid yang anaknya akan masuk SD, dan pembuat kebijakan. Hasil penelitiannya mengangkat 3 tema terkait kesiapan sekolah, yaitu mendapatkan sekolah favorit, isu-isu profesionalitas, serta kebijakan nasional dan akuntabilitas.

Dalam hal kebijakan nasional, standar penerimaan peserta didik baru (PPDB) menuju sekolah dasar diatur dalam Peraturan Menteri Pendidikan dan Kebudayaan (Permendikbud) Nomor 17 tahun 2017 pasal 5. Permendikbud tersebut menyebutkan bahwa peserta didik baru yang sudah berusia 7 tahun wajib diterima. Namun terdapat pengecualian syarat usia di bawah 6 tahun untuk anak-anak yang memiliki kecerdasan istimewa atau memiliki kesiapan belajar yang dibuktikan dengan rekomendasi tertulis dari psikolog profesional. Apabila psikolog profesional yang dimaksud pada ayat sebelumnya tidak tersedia, lebih lanjut dinyatakan bahwa rekomendasi dapat dilakukan oleh dewan guru (Kemendikbud, 2017). Peraturan Menteri tersebut menjadi hal yang perlu diperhatikan oleh seluruh multidisipliner, termasuk guru.

Guru Raudhatul Athfal (RA) sebagai lembaga prasekolah berbasis Islam juga memiliki peran besar dalam mempersiapkan transisi anak menuju masa sekolah dasar. Anak yang secara fisik dan intelektual telah siap untuk sekolah mempunyai sikap yang lebih positif sehingga akan lebih mungkin berhasil di sekolah (Arnold, 2004; Consultative Group on Early Childhood Care and Development, 2008). Sebaliknya, anak yang belum siap sekolah namun direkomendasikan untuk melanjutkan sekolah dasar, dikhawatirkan dapat menimbulkan berbagai masalah di kemudian hari. Penelitian Sulisyaningsih (2005) menjelaskan beberapa contoh perilaku yang terjadi pada anak yang memiliki masalah karena ketidaksiapan sekolah, diantaranya perilaku menarik diri, acuh tak acuh, sakit fisik, atau kesulitan lain dalam menyelesaikan tugasnya di sekolah (Sulistyaningsih, 2005). Fakta tersebut menunjukkan bahwa pemahaman guru prasekolah terhadap 
konsep kesiapan sekolah memiliki dampak yang signifikan dalam membangun kesiapan anak. Penelitian ini akan menggali lebih dalam terkait pemahaman guru RA dalam memahami kesiapan sekolah anak di wilayah yang menekankan syariat Islam.

\section{KAJIAN TEORITIK}

Pemahaman

(understanding) termasuk ke dalam salah satu dari enam jenjang proses berpikir. Brown (2007) menyatakan "understanding is essentially a theory that explicates the construct". Pada dasarnya, pemahaman adalah teori yang menjelaskan sebuah konstruksi. Artinya, seseorang dikatakan paham ketika ia mampu menangkap arti atau makna dari suatu materi.

Begitu pula dalam hal pemahaman terhadap kesiapan sekolah. Kesiapan merupakan keadaan yang tersiapkan dan terbekali siap untuk melakukan, langsung bertindak, atau menggunakan sesuatu (Seefeldt \& Wasik, 2007). Sedangkan kesiapan sekolah menurut Kagan (1990) adalah seperangkat persyaratan standar atau prasyarat keterampilan fisik, intelektual dan / atau sosial yang dibutuhkan agar anak-anak dapat memenuhi persyaratan lingkungan sekolah. Pendapat tersebut mengandung arti bahwa memiliki kesiapan sekolah menjadi kekuatan seseorang dalam merespon lingkungan sekolah melalui cara tertentu.

National Education Goals Panel (NEGP) menyebutkan bahwa kesiapan bersekolah anak meliputi 5 dimensi yaitu 1). Kesehatan fisik dan perkembangan motorik, 2). Perkembangan social dan emosional, 3). Perkembangan bahasa, 4). Pendekatan untuk belajar, 5). Kognitif dan pengetahuan umum (Kagan, Moore, \& Bredekamp, 1998). Kelima dimensi tersebut memiliki kaitan yang sangat erat antara satu sama lain dan dipengaruhi oleh berbagai faktor. The United Nations World Fit for Children (WFFC) juga menyatakan bahwa kesiapan sekolah adalah kemampuan yang dimiliki seorang anak yang memungkinkan anak bertahan dalam lingkungan sekolah yang aman dan nyaman secara holistik yang meliputi 5 dimensi (Unicef, 2012). Untuk mendapatkan suasana sehat, aman dan nyaman, kesiapan sekolah tidak terlepas dari pengaruh beberapa faktor. National School Readiness Indicators Initiative (NSRII, 2008) dengan tim koalisi dari 17 negara bagian menjelaskan bahwa keberhasilan kesiapan sekolah dengan mempertimbangkan faktor: ready families (keluarga yang siap), ready communities (komunitas yang siap), dan ready schools (sekolah yang siap). 
Pemahaman Guru Prasekolah......

Syarfina, Elindra, dan Lara Fridani

umum tentang kesiapan sekolah, (2) keterampilan dasar yang perlu dimiliki anak dalam hal kesiapan sekolah, (3)

\section{METODOLOGI PENELITIAN}

Penelitian ini menggunakan pendekatan kualitatif. Pendekatan kualitatif adalah penelitian yang menggunakan pendekatan naturalistik untuk mencari dan menemukan pengertian atau pemahaman tentang fenomena dalam suatu konteks (Kirk \& Miller, 1986). Data dikumpulkan dengan menggunakan kuesioner dan dianalisis secara deskriptif.

\section{Tempat penelitian}

Penelitian ini dilakukan di kota Langsa, salah satu kota madia yang terletak di wilayah timur Provinsi Aceh dan berada kurang lebih 430 km dari ibu kota Aceh. Kota Langsa terdiri dari 5 kecamatan, Langsa Barat, Langsa Kota, Langsa Timur, Langsa Lama, dan Langsa Baru.

\section{Subjek Penelitian}

Subjek dalam penelitian ini adalah 58 guru yang mengajar di Raudhatul Athfal (RA) yang tersebar di 13 RA di kota Langsa.

\section{Teknik Analisis Data}

Pertanyaan dalam kuesioner disajikan dengan soal essai terbuka untuk mengetahui (1) pemahaman guru secara kegiatan yang perlu dilakukan dan material yang perlu digunakan untuk mendukung kesiapan sekolah anak, (4) cara gurumenilai kesiapan sekolah anak, (5) faktor yang dapat mempengaruhi kesiapan sekolah anak. Pertanyaan terbuka memberikan informasi lebih mendalam tentang subjek penelitian (Yıldırım \& Şimşek, 2005 dalam Pekdogan, 2017). Setelah mendapat jawaban dari responden, data dianalisis secara deskriptif. Tujuan dari analisis deskriptif adalah untuk mereformasi data dengan cara yang dapat dipahami. Dalam proses analisis data, peneliti mengkodekan jawaban guru dengan pendapat $(\mathrm{P})$.

\section{HASIL DAN PEMBAHASAN \\ Hasil}

Hasil dari 5 pertanyaan kuesioner adalah sebagai berikut:

Pertanyaan nomor 1 tentang "apa yang dimaksud dengan kesiapan sekolah" dirancang untuk melihat pemahaman guru secara umum dalam memaknai kesiapan sekolah. Hasilnya menunjukkan bahwa kesiapan sekolah dipahami oleh sebagian besar guru RA sebagai kesiapan yang dimiliki anak untuk bersekolah yang dilihat dari segi umur, 
kemampuan kognitif, dan bahasa. Para guru berpendapat bahwa anak yang sudah cukup umur, memiliki kemampuan mengenal huruf dan angka, menulis dan berhitung merupakan anak yang memiliki kesiapan sekolah. Pendapat guru tersebut diantaranya:

"Kesiapan sekolah yaitu anak sudah siap untuk masuk ke jenjang sekolah dasar baik dari segi umur maupun kemampuan kognitifnya, misalnya bisa mengenal huruf dan angka.”

"Yang saya pahami tentang kesiapan sekolah secara umum anak siap masuk ke sekolah dasar berdasarkan usia, karena ada keterkaitan antara usia dengan kematangan untuk belajar membaca, menulis, dan berhitung. Meski perkembangan anak berbeda-beda, tapi dalam kenyataannya anak dikatakan siap jika sudah bisa membaca, menulis dan berhitung."

Namun ada pula yang beranggapan bahwa kesiapan sekolah pada anak artinya anak sudah memiliki minat belajar yang tinggi dan mampu konsentrasi lebih lama selama proses pembelajaran.

"Kesiapan sekolah anak adalah kondisi dimana anak telah memiliki keinginan untuk belajar dan terlibat dalam lingkungan belajar tanpa merasa tertekan."

"Kesiapan sekolah adalah anak punya kemauan belajar dan bisa memusatkan perhatiannya meskipun lama pada pembelajaran."

Selain itu, ada pula guru yang menganggap kesiapan sekolah sebagai persiapan terpenuhinya perlengkapan sekolah, misalnya baju seragam, buku, alat tulis, serta sarana dan prasana yang dibutuhkan anak. Sebagaimana pendapat guru:

"Yang saya pahami tentang kesiapan sekolah anak adalah mempersiapkan baju seragam, mempersiapkan buku, alat tulis, alat dan bahan belajar, serta mempersiapkan mainan, sarana dan prasarana sekolah.”

"Kesiapan sekolah adalah mempersiapkan peralatan sekolah dan tempat untuk anak bersekolah."

Pertanyaan nomor 2 tentang "keterampilan dasar yang perlu dimiliki anak agar siap sekolah" dirancang untuk melihat sejauh mana guru memahami standar keterampilan dasar anak-anak dalam memulai sekolah. Hasil temuan menunjukkan terdapat klasifikasi keterampilan yang menjadi fokus guru, yaitu keterampilan harian (untuk melakukan aktivitas sehari-hari) dan 
Pemahaman Guru Prasekolah......

Syarfina, Elindra, dan Lara Fridani

keterampilan dari segi aspek perkembangan yang disajikan dalam tabel berikut:

Keterampilan dasar yang perlu dimiliki anak agar siap sekolah

a. Keterampilan harian anak meliputi:

- $\quad$ Bangun pagi

- $\quad$ Mandi sendiri

- Makan sendiri

- $\quad$ BAK /BAB sendiri

- Mengikat tali sepatu sendiri,

- Memakai pakaian sendiri.

b. Keterampilan dari segi aspek perkembangan

Fisik motorik memegang pensil, berjalan dan berlari.

Soial emosioanal

Bermain bersama teman, mengikuti aturan, berani tampil depan kelas, bertanggung jawab.

Bahasa

Mampu berkomunikasi, mampu membaca dan menulis.

Kognitif

Mengenal huruf, mengenal
angka, mengenal warna,
mengenal pola, mengenal
alam sekitar, mengenal
anggota tubuh.

Pertanyaan nomor 3 tentang "kegiatan dan material yang mendukung kesiapan sekolah anak" dirancang untuk mengetahui pemahaman guru dalam memilih kegiatan, metode, serta bahan ajar untuk membangun kesiapan sekolah anak. Hasilnya menunjukkan bahwa guru lebih sering mengaplikasikan kegiatan bermain dan bernyanyi, serta field trip. Sedangkan untuk pilihan material, guru menggunakan alat berupa warna, alat peraga, boneka tangan, kartu, dan balok. Pilihan kegiatan tersebut didasarkan pada jawaban guru seperti:

"Bermain mengenalkan angka dan huruf secara sederhana, mengaji, menulis, dengan menggunakan material kartu dan balok."

"Kegiatan baris berbaris, senam yang menyenangkan agar anak senang dan sehat, melatih motorik dengan kegiatan berlari, juga bernyanyi. Material berupa warna, boneka."

"Material yang digunakan untuk mendukung kesiapan sekolah anak adalah alat peraga"

"kegiatan yang mengajarkan mandiri dan tanggung jawab. Bekerja sama dengan orang tua untuk kegiatan yang bertujuan melatih kedispilinan."

"Field trip, kunjungan studi banding kesekolah dasar." 
Pertanyaan nomor 4 tentang "cara menilai kesiapan sekolah anak" dirancang untuk melihat pemahaman guru dalam menilai anak yang siap sekolah. Hasilnya menunjukkan bahwa guru melakukan observasi dan evaluasi tugas. Namun obervasi yang dilakukan cenderung kepada aspek perkembangan kognitif. Selain kognitif, observasi lainnya pada kesehatan anak, keterampilan harian, keinginan anak pada sekolah, serta mempertimbangkan usia anak. Sebagaimana pendapat guru yang menyatakan:

"Saya melihat sejauh mana anak mempunyai keinginan untuk bersekolah.”

"Penilaian dilihat apakah anak sudah siap dari aspek kognitif, motorik, sosial emosional, dan bahasa."

"Saya melakukan penilaian dengan mengobservasi dan pemberian tugas.” "Saya melihat sejauh mana anak terbiasa mandiri dan punya keinginan untuk sekolah."

"Saya melakukan evaluasi dengan menggunanakan observasi, hasil karya dari unjuk kerja, dan praktek langsung."

Pertanyaan nomor 5 tentang "faktor yang mempengaruhi kesiapan sekolah anak" dirancang untuk melihat pemahaman guru terhadap faktor apa saja yang dapat mempengaruhi kesiapan sekolah anak. Hasilnya menunjukkan bahwa guru secara garis besar menyatakan keluarga sangat mempengaruhi kesiapan sekolah anak, baik dari segi pola asuh, status ekonomi, pendidikan orang tua, dan status perkawinan (orang tua yang bercerai, single parent). Meskipun adapula guru yang berpendapat bahwa kesiapan sekolah anak dipengaruhi oleh anak itu sendiri yang mencakup aspek perkembangannya, lembaga prasekolah, dan lingkungan. Seperti pernyataan guru sebagai berikut:

"Faktor dari keluarga yang paling utama dalam mempengaruhi kesiapan sekolah anak."

"Faktor lingkungan dan keluarga yang kurang perhatian."

"Orang tua dan perkembangan anak itu sendiri.",

"Kesiapan orang tua dan lingkungan."

"Faktor keluarga, lingkungan dan prasekolah."

\section{Pembahasan}

Dari hasil yang telah dipaparkan mengenai pemahaman guru dari lima hal yang menjadi indikator, guru memahami kesiapan sekolah lebih menitikberatkan pada aspek koginitif dan literasi seperti 
membaca, menulis, dan berhitung. Berdasarkan kajian literatur tentang kesiapan sekolah (Kagan, 1990), dimensi kesiapan sekolah seharusnya melibatkan berbagai aspek perkembangan, seperti kognitif, motorik, bahasa, social emosional juga dilihat dari segi kesehatan fisik dan pendekatan untuk belajar. Selain itu, guru juga lebih memprioritaskan kesiapan sekolah dari faktor usia. Bahkan ada yang memahami kesiapan hanya seputar mempersiapkan perlengkapan sekolah tanpa melihat kesiapan mental anak.

Untuk segi keterampilan yang harus dimiliki sebelum mulai sekolah, guru sudah memiliki pemahaman yang luas dalam hal kemandirian serta keterampilan harian di setiap aspek perkembangan. Perawatan diri dasar, kematangan sosial, pengaturan diri, komunikasi dengan teman sebaya, keterampilan motorik, informasi kognitif, komunikasi dan adaptasi dalam kelas secara signifikan menjadi hal yang perlu diperhatikan dalam membangun kesiapan sekolah anak-anak (Piotrkowski, Botsko, dan Matthews, 2000).

Selanjutnya dalam membangun kesiapan sekolah, guru sudah mengedepankan permainan meskipun masih terbatas dalam menciptakan permainan kreatif. Sistem belajar yang mengedepankan "play" dapat membuat anak larut dalam suasana belajar tanpa mengenal waktu. Hal tersebut dapat menciptakan suasana senang dan antusias dalam belajar. Bermain menjadi penting karena pendekatan menuju pembelajaran menekankan aspek tingkat perhatian anak, keterlibatan, dan ketekunan saat mereka melakukan berbagai tugas nanti di sekolah (Alexander dan Dauber, 1993).

Adapun cara yang dilakukan guru dalam menilai tingkat kesiapan sekolah anak adalah melakukan observasi dan evaluasi hasil karya. Hal tersebut menunjukkan bahwa guru tidak hanya melihat proses tapi juga melihat hasil akhir dari tugas yang diberikan, sedangkan pengetahuan anak merupakan akumulasi dari berbagai proses, misalnya dalam memecahkan masalah, dalam menggunakan strategi tertentu, dalam memperdulikan teman, keluarga, lingkungan dan alam, serta dalam berimajinasi (Jalongo dalam kagan, 1998).

Keluarga, terutama orang tua, sebagai orang terdekat dengan anak memiliki pengaruh besar pada semua dimensi kesiapan sekolah. Selain itu, keterlibatan keluarga dan lingkungan belajar menjadi 
penentu yang lebih signifikan bagi kesiapan sekolah anak (Sheridan, Knoche, Edwards, Bovaird, \& Kupzyk, 2010). Hal tersebut sejalan dengan apa yang guru-guru pahami tentang faktor kesiapan sekolah.

\section{KESIMPULAN DAN SARAN}

Dengan mengetahui sejauh mana pemahaman guru RA di suatu daerah dalam memahami kesiapan sekolah, akan diperoleh gambaran tentang pentingnya menentukan cara atau strategi untuk meningkatkan pemahaman para guru tentang kesiapan sekolah. Konsen kesiapan sekolah tidak hanya berpusat pada anak dan melakukan asesmen kesiapan pada anak, namun juga dapat mengembangkan cara guru dalam membangun kesiapan anak.

Penelitian ini diharapkan dapat memberikan kesadaran pada para pendidik untuk dapat meningkatkan wawasan dan kompetensinya terkait kesiapan sekolah serta memberi masukan kepada para pemegang kebijkan untuk lebih memperhatikan kualitas dan profesionalitas guru. Studi yang melibatkan aspek kesiapan sekolah berbeda lainnya dapat dilakukan oleh kelompok sampel lain.

\section{DAFTAR PUSTAKA}

Alexander, K. L., Entwisle, D. R., \& Dauber, S. L. (1993). First-grade classroom behavior: Its short-and long-term consequences for school performance. Child development, 64(3), 801-814.

Arnold, C. (2004). Positioning ECCD in the 21 st century. Coordinators' notebook, 28(1), 1-36.

Brown, Douglas. (2007). Principle of Language Learning and Teaching. San Fransisco State University: Longman.

Center for the Study of Social Policy (Washington, DC), Kagan, S. L., \& Rigby, D. E. (2003). Improving the readiness of children for school: Recommendations for state policy: A discussion paper for the Policy Matters Project. Center for the Study of Social Policy.

Fridani, Lara. (2013). Rethinking school readiness and transition policy and practice in early childhood education (ECE): a whole schooling framework. The International Handbook of 
Pemahaman Guru Prasekolah......

Syarfina, Elindra, dan Lara Fridani

Cultures of Education Policy

Vol 1 (1): Comparative

International Issues in Policy-

Outcome Relationships -

Achievement with Family and

Community Involvement,

Strasbourg, France, 233-245

High, P. C. (2008). School readiness.

Pediatrics, 121(4), e1008e1015.

Hurlock, E. B. (1978). Perkembangan

Anak Jilid 1 (Alih Bahasa:

Meitasari Tjandrasa dan

Muslichach Zarkasih). Jakarta:

Erlangga.

Kagan, S. L. (1990). Readiness 2000:

Rethinking rhetoric and responsibility. The Phi Delta Kappan, 72(4), 272-279.

Kagan, S. L., Moore, E., \& Bredekamp, S. (1998). Reconsidering children's early development and learning toward common views and vocabulary: National Education Goals Panel: DIANE Publishing.

Kirk, J., \& Miller, M. L. (1986). Reliability and validity in qualitative research: Sage.Kagan, S. L. (1990). Readiness 2000: Rethinking rhetoric and responsibility. The Phi Delta Kappan, 72(4), 272279.
Kagan, S. L., Moore, E., \& Bredekamp, S. (1998). Reconsidering children's early development and learning toward common views and vocabulary: National Education Goals Panel: DIANE Publishing.

Kirk, J., \& Miller, M. L. (1986). Reliability and validity in qualitative research: Sage.

Scott-Little, C., Kagan, S. L., \& Frelow, V. S. (2006). Conceptualization of readiness and the content of early learning standards: The intersection of policy and research? Early Childhood Research Quarterly, 21(2), 153173.

Seefeldt, C., \& Wasik, B. A. (2007). Early education: Three-, four-, and five-year-olds go to school: Recording for Blind \& Dyslexic.

Sulistyaningsih, W. (2005). Kesiapan bersekolah ditinjau dari jenis pendidikan pra sekolah anak dan tingkat pendidikan orangtua. Psikologia, 1(1), 8.

Sheridan, S. M., Knoche, L. L., Edwards, C. P., Bovaird, J. A., \& Kupzyk, K. A. (2010). Parent engagement and school readiness: Effects of the Getting Ready intervention on preschool children's social-emotional 
competencies. Early Education and Development, 21(1), 125156.

Parker, F. L., Boak, A. Y., Griffin, K. W., Ripple, C., \& Peay, L. (1999). Parent-child relationship, home learning environment, and school readiness. School Psychology Review, 28(3), 413.

Piotrkowski, C. S., Botsko, M., \& Matthews, E. (2000). Parents' and teachers' beliefs about children's school readiness in a high-need community. Early Childhood Research Quarterly, 15(4), 537-558

Peraturan Menteri Pendidikan dan Kebudayaan (Permendikbud) Nomor 17 tahun 2017 tentang PPDB, Pasal 5, ayat 1-3

Unicef. (2012). School readiness: A conceptual framework. New York. United Nations Children's Fund. 